\title{
Práticas complementares, racionalidades médicas e promoção da saúde: contribuições poucos exploradas
}

\author{
Complementary practices, medical rationalities, \\ and health promotion: some overlooked \\ contributions
}

\author{
${ }^{1}$ Centro de Ciências da \\ Saúde, Universidade \\ Federal de Santa Catarina \\ Florianópolis, Brasil. \\ Correspondência \\ C. D. Tesser \\ Departamento de Saúde \\ Pública, Centro de Ciências \\ da Saúde, Universidade \\ Federal de Santa Catarina. \\ Campus Universitário - \\ Centro de Ciências da Saúde \\ Florianópolis, SC \\ 88040-900, Brasil. \\ charlestesser@ccs.ufsc.br
}

\begin{abstract}
This article presents some key contributions to health promotion by complementary and alternative medicine (CAM). After contextualizing $C A M$, the article proposes a scheme for viewing the challenges and tensions in health promotion, organized along four thematic lines: (1) actions impacting the collective (social, collective "empowerment") versus the individual; (2) intersector versus sectorial actions; (3) positive and expanded conception of health versus health as absence of disease; (4) directive versus dialogical pedagogy. The paper argues that the contributions of CAM to health promotion are oriented towards individuals and groups and to the sectorial pole of promotion; they are centered on positive conceptions of health, especially vitalist medical paradigms, including health-strengthening practices; and with "empowering" pedagogical potential. The article highlights the relevance of these contributions, largely overlooked in the past, and the difficulties and guidelines for enabling them in Brazil, related to their nonscientific and poorly institutionalized configurations and their steady commodification.
\end{abstract}

Complemetary Therapies; Health Promotion; Professional Practice
Charles Dalcanale Tesser 1

\section{Introdução}

Este artigo tem por objetivo apresentar contribuições do campo das práticas complementares em saúde-doença, mais comumente conhecido como medicinas alternativas e complementares (MAC) ou práticas integrativas e complementares (PIC) à promoção da saúde no ambiente do Sistema Único de Saúde (SUS). Trata-se de um ensaio que sistematiza as contribuições desse campo para a promoção da saúde, dado que ambos têm crescido e se fortalecido mais ou menos em paralelo nas últimas décadas e apresentam várias intersecções e pontos em comum, embora pouco explorados.

A hipótese central, baseada tanto na literatura quanto em experimentações individuais, coletivas e institucionais dispersas no SUS, é que várias práticas complementares e seus praticantes portam saberes/técnicas especificamente voltados à promoção da saúde, que podem ser instrumentos/aliados nas missões a que se propõe esta última. Todavia, a exploração acadêmica do campo das MAC tem repercutido pouco sobre a saúde coletiva e o SUS, a ponto de apenas em 2006 ter havido uma política nacional a respeito 1 . Isso torna relevante a reflexão sobre as convergências e imbricações, teóricas e práticas, entre o campo das MAC ou PIC e a promoção da saúde. Contribuir para o reconhecimento, compreensão e exploração dessas imbricações é o fio condutor deste ensaio. 


\section{Sobre práticas complementares e racionalidades médicas}

As MAC são diversos sistemas médicos e de cuidado à saúde, práticas e produtos que não são presentemente considerados parte da medicina convencional 2. Obviamente, esse conjunto é genérico e heterogêneo demais, reunindo sob uma mesma etiqueta ingredientes muito diferentes. No Brasil, Luz ${ }^{3}$ produziu uma matriz de análise de formas de cuidado à saúde útil para consideração desse conjunto. Trata-se da categoria "racionalidade médica”, construída como um tipo ideal weberiano, definida como um conjunto estruturado e coerente de cinco dimensões interligadas: uma morfologia do homem (anatomia), uma dinâmica vital (fisiologia), um sistema de diagnose, um sistema terapêutico e uma doutrina médica (explicativa dos adoecimentos, sua origem e cura), embasadas em uma cosmologia implícita ou explícita. O estudo de sistemas de cuidado por meio dessas dimensões permitiu distinguir entre sistemas médicos complexos (racionalidades médicas), como a biomedicina, a medicina ayurvédica ou a medicina tradicional chinesa, de terapias ou métodos diagnósticos, como os florais de Bach, a iridologia, o reiki, entre outros.

Assim, nas MAC existem práticas que podem estar ou não afiliadas a uma racionalidade médica e podem ainda estar inseridas em uma matriz histórico-cultural e ou tradicional mais ampla, como as medicinas tradicionais da China ou da Índia, por exemplo, identificadas então como medicinas tradicionais (MT) ${ }^{4}$. Usamos o rótulo MAC para designar o campo inespecífico de tais práticas, incluídas ou não em racionalidades médicas, apenas e somente por ele estar já consagrado na literatura internacional e na pesquisa biomédica. Buscamos, entretanto, uma especificação na designação das mesmas na medida do possível, dentro da generalidade desta apresentação.

As MAC/MT continuam respondendo, nos países pobres, por grande parte do cuidado em saúde que transcende o ambiente familiar; em vários lugares (África, por exemplo), pela maior parte. Nos países ricos, proliferam estudos que vêm mostrando grande procura de suas populações pelas MAC. Além disso, cada vez mais profissionais de saúde indicam práticas complementares e também procuram aprendê-las para "enriquecer" suas habilidades curadoras 4,5,6,7. Em que pese sempre ter havido, no Brasil, legitimidade e procura popular dessas práticas 8,9, há um reconhecimento recente de uma maior procura no ocidente por elas.

Os motivos da procura nos países pobres seriam sua adequação cultural, fácil acesso e eficácia relativa associados ao pequeno acesso à biomedicina, escassa e cara nesses lugares 3 . Nos países ricos, há dois tipos de motivos para essa procura crescente, um associado a insatisfações com a biomedicina e outro com os méritos próprios das práticas complementares e tradicionais.

As insatisfações se devem aos limites diagnósticos (o saber científico biomédico é um saber de resolução "grosseira" 10,11, sua prática não consegue interpretar, ignora e desqualifica uma grande parte dos sintomas "não enquadráveis"), aos limites terapêuticos (as tecnologias de tratamento são restritas, para muitos diagnósticos há severos limites de eficácia terapêutica, restrita ao controle de doenças ou sintomas, por vezes há ausência de terapêutica) e às iatrogenias (os efeitos adversos são por demais relevantes, muito acentuados com o envelhecimento populacional, com a maior prevalência das doenças crônicas e com o processo de medicalização social, que intensifica o uso de quimioterápicos para cada vez mais experiências da vida; por exemplo, as iatrogenias - incluindo os erros médicos - tornaram-se a terceira causa de morte nos Estados Unidos 12). Há ainda uma insatisfação difusa e crescente com a abordagem biomédica, caracterizada como mecanicista, materialista, invasiva, intervencionista, restrita aos sintomas e progressivamente mais impessoal, dedicando pouco tempo ao paciente. Neste caso, a relação curador-doente parece estar ficando menos harmoniosa, a fragmentação tende a tecnificar o cuidado, reduzi-lo aos aspectos do adoecimento e partes do corpo classificáveis e manipuláveis pela tecnologia científica, e assim “desumanizá-lo". Com isso, fica prejudicado o pacto ancestral envolvido na "relação de cura", construído sobre compromissos éticos calcados na pessoa do doente. Em outras palavras, tratase da insatisfação com a baixa integralidade da atenção biomédica 13 .

Por outro lado, os méritos das práticas complementares estão obtendo reconhecimento da população, da sociedade formal e em parte da ciência biomédica; particularmente quanto à experiência com o processo adoecimento-cuidado-cura e quanto ao estímulo do potencial de reequilíbrio e cura do próprio paciente ${ }^{14}$, com uma relação de maior solidariedade e proximidade entre curador-doente, maior satisfação com a abordagem filosófica, cosmológica e de significação (holística) dos adoecimentos proporcionada no campo das MAC, denotando certa convergência entre os valores e crenças dos usuários com as mesmas 4,15,16,17,18,19,20. 


\section{A promoção da saúde}

A promoção da saúde é um campo de propostas, idéias e práticas, crescente na saúde pública, que parte de uma concepção ampla do processo saúde-doença e de seus determinantes e propõe a articulação de saberes técnicos e populares e a mobilização de recursos institucionais e comunitários, públicos e privados para seu enfrentamento e resolução 21 .

Este movimento ganhou força em 1986, com a I Conferência Internacional sobre Promoção da Saúde, no Canadá, que formalizou a Carta de Ottawa, documento histórico que se constitui num marco de referência desse campo discursivo, cujas propostas delimitaram os principais campos de ação da promoção da saúde: (1) elaboração e implementação de políticas públicas saudáveis; (2) criação de ambientes favoráveis à saúde; (3) reforço da ação comunitária; (4) desenvolvimento de habilidades pessoais e (5) reorientação do sistema saúde. Várias conferências internacionais ocorreram nestes vinte anos, ressaltando um ou outro aspecto ou temática, mas sem alterar significativamente os contornos do campo 22.

No Brasil, o movimento da promoção da saúde cresceu, com várias experiências municipais e no SUS e discussões acadêmicas sobre os significados, limites e disputas internas desse movimento e sua inserção na situação brasileira 22,23,24,25,26. Mas, coincidentemente, apenas em 2006 foi editada uma política nacional sobre o tema. A Política Nacional de Promoção da Saúde tem como objetivo geral promover a qualidade de vida e reduzir vulnerabilidade e riscos à saúde relacionados aos seus determinantes e condicionantes - modos de viver, condições de trabalho, habitação, ambiente, educação, lazer, cultura, acesso a bens e serviços essenciais 27 . Nota-se uma convergência da política nacional brasileira com os campos de atuação da promoção da Carta de Ottawa e também a prioridade para a ação política, social, institucional, intersetorial e comunitária.

Podemos vislumbrar quatro eixos temáticos bipolares com os quais podem ser demarcadas propostas, práticas e tensões internas da promoção da saúde, quanto às suas ações, referenciais epistemológicos e perspectivas pedagógicas. Tais eixos permitem um mapeamento de saberes, perspectivas, discussões e práticas envolvidas na promoção da saúde, com complementaridade e, por vezes, disputas entre seus pólos, em geral assimétricos. Esse mapeamento facilita a consideração das contribuições das MAC à promoção da saúde.

O primeiro eixo refere-se, em um pólo, a focar a ação da promoção da saúde nos indivíduos, na reorientação de hábitos e comportamentos, desenvolvimento de "habilidades pessoais" e de estilos de vida saudáveis, envolvendo componentes educativos e sob controle maior dos indivíduos, como por exemplo, o hábito de fumar e atividades físicas e dietéticas. Pela abordagem biomédica dos riscos, a promoção da saúde individual e seu "estilo de vida saudável" vem-se apresentando como importante para a promoção da saúde. Apesar de esse discurso/prática ser muito criticável, como em Castiel \& Diaz 28, talvez a maior parte dos projetos, intervenções, tecnologias e pesquisas da biomedicina ligadas ao campo da promoção da saúde e da prevenção de doenças dirijam-se a este pólo do primeiro eixo, dominando a formação profissional na saúde e a ação dos profissionais no SUS.

No outro pólo deste primeiro eixo está a ênfase no campo social. Este pólo, para Buss 21,22, é o que caracteriza ou deve caracterizar a promoção da saúde modernamente. A ênfase na determinação social da saúde-doença leva a ações institucionais, intersetoriais, políticas e culturais que visam o empowerment pessoal e coletivo, participação social e política, solidariedade, construção de ambientes saudáveis, combate a desigualdades, injustiças e iniqüidades sociais, almejando mudanças sócio-políticas, culturais e de valores por uma sociedade mais justa, saudável e sustentável. Para Sutherland \& Fulton 29, esta tensão é o grande divisor de águas da promoção da saúde: ação individual $v s$. social. O pólo social-coletivo é ressaltado no discurso da saúde coletiva brasileira $22,24,26,28$, a esfera individual (desenvolvimento de habilidades pessoais) é mencionada apenas uma vez nas diretrizes da política nacional brasileira a respeito, sendo também apenas um dos cinco campos de atuação da promoção da Carta de Ottawa.

Ainda que seja defensável uma ênfase especial no pólo social, especialmente no Brasil, é inevitável reconhecer que deve haver uma complementaridade entre esses pólos, para que ações intersetoriais e políticas comuniquem-se melhor com o âmbito microssocial e as pessoas. Os sujeitos e sua subjetividade devem poder aparecer na promoção da saúde ${ }^{23,30}$, que requer e se beneficia da ação voltada para os indivíduos e pequenos grupos, em que a atividade dos profissionais de saúde do SUS tem papel relevante e complementar a ações de maior escala e outra dimensão.

O segundo eixo refere-se à questão intersetorialidade $v s$. setorialidade. $\mathrm{O}$ discurso promocionista sanitário brasileiro tende ao pólo intersetorial, priorizando a construção de projetos e ações político-institucionais intersetoriais, em que o setor saúde tem papel relativo ou pequeno 24 . Já o 
segundo pólo deste eixo leva a ação para o campo institucional e profissional da saúde. Claro está que ambos os pólos devem se complementar, realizando coisas que cada um isoladamente não consegue, embora o setor saúde tenha dificuldade em trabalhar articulado intersetorialmente, pois tradicionalmente opera autocentrado, voltado para doenças e sua prevenção e mais na dimensão individual.

O terceiro eixo refere-se a questões epistemológicas relativas aos problemas da conceituação da "saúde". Ele apresenta em um de seus pólos uma conceituação ampliada e positiva de saúde, multidisciplinar e centrada na determinação social do processo saúde-doença. Tal pólo tende a desviar-se do terreno setorial da saúde, associando-se ao pólo intersetorial do segundo eixo e ao pólo social do primeiro. No outro pólo deste eixo, encontramos a saúde como trabalhada no setor saúde, capitaneado pela biomedicina e os saberes biomédicos, em que saúde é vista como a ausência de doença 31 , a qual, esta sim, é definida e operacionalizada na prática clínica e sanitária. São mobilizados, então, conceitos e tecnologias da clínica e da saúde públicas, que objetivam diminuir riscos e prevenir e tratar precocemente doenças específicas. Esse pólo tende a aproximar a promoção da prevenção de doenças, do trabalho setorial e da dimensão individual. Se ele permite operacionalizar prevenções, tratamentos e promoções em algum grau, deve-se reconhecer que ele é restrito na promoção, padecendo de certo reducionismo biologicista já muito criticado. Sua ação é altamente desejável, mas parece ser um pólo fraco na promoção da saúde, ainda que mais atuante na dimensão individual relacionada a doenças específicas e recentemente riscos, dominando a formação dos profissionais e sua prática no SUS.

O quarto e último eixo da promoção da saúde refere-se, em um pólo, à perspectiva comunicativa e educativa da promoção da saúde, e às suas ambições de empowerment, para que indivíduos e coletividades possam participar ativamente na construção de uma vida e uma sociedade mais saudável. Tais ambições exigem uma prática educativa centrada no diálogo, na solidariedade, na construção de parcerias, fomentando a co-responsabilidade e a politização individual e coletiva. Aqui aparece um grande desafio e tensão, uma vez que no pólo oposto deste eixo encontra-se uma tradição pedagógica hegemônica na saúde pública e na biomedicina diretiva, autoritária, controladora e vinculada a uma perspectiva de enquadramento dos indivíduos e comunidades em ordens sociais e comportamentos ditados tecnocraticamente ou politicamente alhures.
Neste eixo também encontramos outra ambigüidade ou polaridade, presente nos significados do termo e das propostas de empowerment. Há um significado comportamentalista e individualista, chamado por Carvalho 32 de empowerment psicológico, focado no indivíduo e na sensação individual de segurança e controle sobre sua vida pessoal, enfatizando o pertencimento a um grupo, a sensação de autoconfiança e a harmonia com o meio social. Ações de promoção de saúde com este enfoque tendem a valorizar estratégias para resgate e aumento de auto-estima, capacidade de adaptação ao meio e auto-ajuda, mas podem desconectar artificialmente a pessoa do contexto sócio-político em que está inserida, reforçando um conservadorismo social e cultural, por vezes em situações sociais injustas em que as vítimas são responsabilizadas, para não dizer culpabilizadas. Esse enfoque pode esconder uma perspectiva educativa em saúde controlista e instrumentalizar políticas sociais neoliberais restritivas, acirradoras da iniqüidade social.

Outro significado, mais amplo, o chamado empowerment comunitário, toma por base uma noção de poder como recurso, material e imaterial, distribuído desigualmente na sociedade, em grupos diversos, no qual convivem dimensões produtivas, potencialmente criativas e instituintes, com elementos de conservação do status quo. Neste enfoque supõe-se alto teor de empowerment psicológico, mas, além disso, fatores associados a distintas esferas da vida microssocial (apoio social, compartilhamento de projetos e interesses pessoais e comunitários, aprendizado social, político e de consciência crítica com essas experiências) e macrossocial (ação coletiva, política e cultural, crítica social etc.) se fazem presentes, e enriquecem a perspectiva político-filosófica de forma coerente com valores de solidariedade, justiça, liberdade, fraternidade, redistribuição de poderes excessivamente concentrados etc. 32 . Este significado ampliado é convergente com uma perspectiva emancipatória e solidária, que assumimos aqui como envolvido e necessário no pólo dialogal desse eixo de dimensão pedagógica das práticas em saúde, que necessita ser desenvolvido, ampliado e fortalecido.

Os quatro eixos podem ser visualizados na Figura 1, que apresenta um mapa esquemático facilitador da visualização das práticas, saberes, propostas e tensões presentes no campo da promoção da saúde. 
PRIMEIRO EIXO

\begin{tabular}{|cc|}
\hline $\begin{array}{c}\text { Ênfase no social e coletivo } \\
\text { (determinação social da saúde-doença) }\end{array}$ & $\begin{array}{c}\text { Ênfase no individual } \\
\text { (desenvolvimento de } \\
\text { habilidades pessoais) }\end{array}$ \\
$\begin{array}{c}\text { Ações comunitárias, institucionais, } \\
\text { intersetoriais, políticas e culturais } \\
\text { que visam ao aumento do } \\
\text { "empoderamento" }\end{array}$ & $\begin{array}{c}\text { Ênfase na reorientação de hábitos } \\
\text { e comportamentos, desenvolvimento } \\
\text { de "habilidades pessoais"e de }\end{array}$ \\
$\begin{array}{c}\text { comunitário, participação social e } \\
\text { política, solidariedade e cidadania }\end{array}$ & $\begin{array}{c}\text { estilos de vida saudáveis } \\
\end{array}$ \\
\end{tabular}

\section{SEGUNDO EIXO}

\section{Ênfase na intersetorialidade}

Construção de projetos e ações político-institucionais intersetoriais, educativas, sociais, econômicas

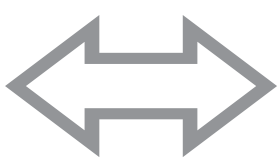

Ênfase nas ações específicas do campo institucional da saúde

\section{TERCEIRO EIXO}

\section{Ênfase na conceituação ampliada} e positiva da saúde

Desvia do terreno setorial biomédico e da saúde pública, dominado pela centralidade nas doenças, seus riscos e prevenção

\section{Ênfase na saúde como ausência da doença}

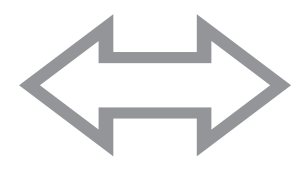

Noção biomédica e clínicoepidemiológica comumente usada na prática médica

e sanitária (epidemiológica), embora muito criticada

\section{QUARTO EIXO}

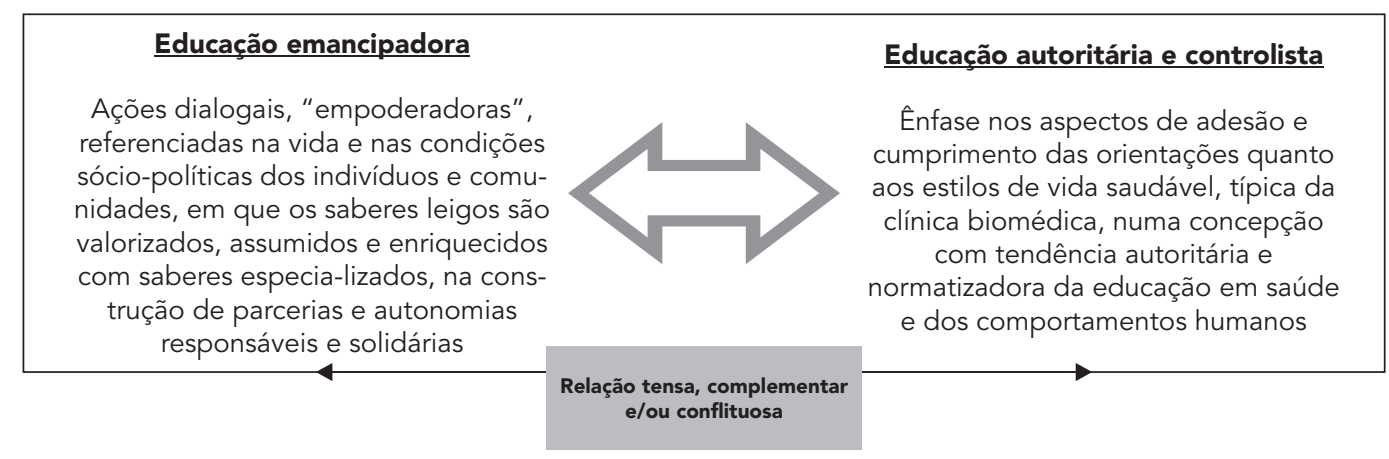


Práticas complementares, racionalidades médicas e promoção da saúde

Observemos que as práticas complementares, desde as antigas até as mais recentes, afiliadas ou não a racionalidades médicas, dedicam-se eminentemente ao cuidado com a saúde dos indivíduos, localizando-se no pólo individual do primeiro eixo. Se a noção de "indivíduo" é uma invenção recente da modernidade européia, devemos reconhecer que o cuidado com a saúde individual, no sentido de voltado para a pessoa, é tradição comum das culturas. A concepção de pessoa pode ser mais relacional que o indivíduo moderno, mas isso não obscurece o fato de que são baseadas nas pessoas e suas relações que as práticas tradicionais e suas racionalidades se desenvolveram. Inclusive, várias racionalidades médicas insistem em que o cuidado com a saúde é um meio para o objetivo final de realização enquanto ser humano (discurso também da promoção da saúde), concebendo um processo de transformação e realização pessoal como trajetória individual, ainda que seja para religar e reharmonizar a pessoa com o cosmo, o mundo, os outros. Esse é o objetivo do caminho das práticas tradicionais do yoga ou do tai chi chuan, inseridas nas racionalidades médicas tradicionais da Índia e da China.

Contudo, é comum que essas racionalidades ofereçam práticas, valores e técnicas de promoção de saúde que se realizam também coletivamente em pequenos grupos e valorizam e fomentam a solidariedade, a troca entre os praticantes, o empowerment comunitário. As meditações, as massagens e automassagens, os exercícios psicofísicos ou energéticos, se bem que voltados para o indivíduo, mostram repercussões positivas na sociabilidade, na construção de redes de apoio social, na discussão da participação social e política 33,34 . Não é por acaso que profissionais do SUS envolvidos com atividades coletivas de tipos variados, inclusive usando técnicas complementares, não raro testemunham que os grupos costumam fomentar cidadãos mais atuantes e mesmo conselheiros locais de saúde. Portanto, é no pólo individual e grupal, numa perspectiva relacional microssocial, que as práticas complementares podem contribuir para a promoção da saúde.

Em relação ao segundo eixo proposto, as práticas complementares e racionalidades médicas geralmente permanecem no "setor saúde" (embora por vezes essas práticas sejam inseridas numa secretaria de cultura ou esportes). Elas se dedicam a permanecer no campo individual e grupal numa ação de fortalecimento, estímulo ou resgate da saúde e de qualidade de vida, para além do tratamento dos adoecimentos.
Quanto ao terceiro eixo, algumas racionalidades médicas vitalistas e suas práticas (homeopatia, medicina tradicional chinesa, medicina ayurvédica, pelo menos) estruturam-se e agem em termos de uma conceituação positiva de saúde. Proporcionam técnicas, saberes e ações especificamente promotoras da saúde e, por vezes, integram com elas cuidados terapêuticos, estimulando potenciais de cura autóctones e fortalecendo a saúde. Isso é permitido, por exemplo, pelo uso de noções como a de "princípio vital" (homeopatia), sopro ou energia vital (chi, dos chineses; prana, dos indianos), que interligam a pessoa interna e externamente, e de técnicas a elas relacionadas 35 . Por misteriosas que possam parecer tais noções para a biociência, é mister reconhecer que elas organizam de modo operacional a promoção e a terapêutica nessas outras racionalidades médicas, e que há aprendizado disciplinado e organizado para compreensão, percepção, treino e uso da "matéria prima" da saúde que é essa "energia vital”, para o cuidado e para a promoção da saúde, como na medicina chinesa 36,37. Essas racionalidades integram noção positiva de saúde com promoção e cuidado terapêutico, missão difícil para os saberes/práticas científicos, partindo do indivíduo em relação (microssocial).

Várias racionalidades médicas, particularmente as tradicionais (mas também as práticas complementares em geral, conformeAndrade 19), têm um potencial pedagógico relevante, incluindo aí um aspecto de autoconhecimento e crescimento pessoal. Elas se baseiam na experimentação individual e coletiva das práticas e cuidados, explorando com maior riqueza (em relação à biomedicina) as ressignificações e aprendizados advindos da experiência do adoecimento, do sofrimento e da revisão de valores comumente aí envolvidos. Na medicina tradicional chinesa, na yoga, em técnicas de meditação, por exemplo, os praticantes exemplificam pela prática pessoal do terapeuta a promoção da saúde. Neste caso, sua pedagogia é centrada na sua própria experiência e na experiência das pessoas, por vezes com estilos comunicativos e valores convergentes com o ideário da promoção da saúde.

Vale comentar a existência de certo senso intelectual que vê apenas dogmatismo, conservadorismo e autoritarismo nas culturas não modernas, em discordância com a valorização positiva sintetizada acima quanto à sua pedagogia dialogal e emancipatória. A generalização dessa questão implica avaliações grosseiras e homogeneizadoras que obscurecem o problema. Nossa hipótese é que vários praticantes filiados a racionalidades médicas vitalistas e tradicionais, $\mathrm{e}$ mesmos outros executores de práticas comple- 
mentares, vivem em si mesmos experiências que os possibilitam desenvolver um razoável grau de sabedoria prática, ética e solidariedade, que deixam seu proceder suficientemente "empoderador", dialogal e promotor de saúde. É claro que posturas autoritárias são também comuns, de modo que as racionalidades médicas vitalistas e as práticas complementares não estão imunes a essa tendência. $\mathrm{O}$ que ressaltamos é que elas portam, sobretudo em seus extratos especializados tradicionais, associados não por acaso à "sabedoria" e à "maestria”, aspectos pedagógicos "empoderadores", sobre o qual podemos tomar como respaldo, por exemplo, as discussões de Jullien 38,39 e de Golemam 40 , ou relatos como de Kaiguo \& Shunchao ${ }^{41}$, sobre culturas orientais tradicionais e suas práticas.

Obviamente, não se deve esperar desses praticantes tradicionais discursos e práticas de $\mathrm{em}$ powerment comunitário explicitamente semelhantes aos modernos, identificados como politizados, reformadores ou transformadores sociais ou culturais (salvo exceções, como em Sarkar) 42. Mas seus valores, discursos e práticas pedagógicas certamente não se restringem ao empowerment psicológico, já que ensinam mediante experiência vivida e valores que transcendem em muito as formações sociais diversas em que nasceram, inclusive com grande similaridade e congruência. A solidariedade, a compaixão, a justiça, a humildade, a flexibilidade, o discernimento e a sobriedade, o desapego, o benefício aos outros seres, o amor - em termos cristãos, a busca da percepção de realidades profundas além das aparências, a valorização do senso crítico, a busca do crescimento e da transformação humana culminando na sua realização, vários desses valores foram e continuam sendo importantes nas práticas e pedagogias dessas racionalidades, que as levam muito além do conservadorismo social, comumente apontando em sentido contrário, embora sem elaborar propostas de mudança de estrutura social. Tais características as aproximam mais do empowerment comunitário (que do psicológico, se utilizarmos estas categorias), mesmo que este linguajar carregue uma cosmovisão nitidamente moderna, alheia a várias culturas tradicionais e suas racionalidades médicas.

Outro aspecto a ser ressaltado, envolvido no empowerment, que transcende em parte a discussão acima ou independe dela, é o fato de que em racionalidades médicas vitalistas existem arcabouços de saberes e práticas individuais de promoção da saúde num sentido estrito e literal de ampliação e reforço da saúde (por exemplo: técnicas de harmonização, fortalecimento, desbloqueio e treino da energia vital, na medicina tradicional chinesa), que simplesmente não têm correlato no saber científico. Elas esperam por pesquisa e exploração no campo do desenvolvimento de habilidades e capacidades pessoais, um dos cinco campos da promoção da saúde, de modo a contribuírem para seu enriquecimento.

Além disso, em algumas dessas práticas e racionalidades médicas há uma valorização do autoconhecimento e uma comunicação mais fácil com valores espirituais das várias culturas, religiões e tradições dos usuários. Algumas já portam valores dessa natureza e possibilitam a incorporação e mobilização de aspectos ditos "espirituais", recentemente revalorizados no ambiente da saúde e desde sempre valorizados no seio das populações 43 .

Experiências clínicas egrupais no SUS, de profissionais, serviços isolados ou municípios, pouco sistematizadas, têm revelado aos poucos essas potencialidades, como por exemplo, em Campinas (São Paulo) 33, São Paulo, Rio de Janeiro, Brasília 34, Belo Horizonte (Minas Gerais) e vários outros; alguns deles expostos no 1o Seminário Internacional de Práticas Integrativas e Complementares realizado pelo Ministério da Saúde em Brasília em julho de 2008 (disponíveis na página eletrônica: http://dtr2004.saude.gov.br/dab/se mi_praticas_integrativas.php). Estes e outros serviços abriram-se para práticas tão diversas como yoga, tai chi chuan, liang gong, reiki, toque terapêutico, grupos de relaxamento e meditação, homeopatia, acupuntura, biodança, automassagens, entre outras. Tais experiências vêm mostrando aceitação da oferta de práticas complementares tanto no plano da promoção como no do tratamento pelos usuários do SUS, o que é coerente com a comum unanimidade local, municipal e nacional na manifestação política dos usuários nos Conselhos de Saúde brasileiros e nas Conferências de Saúde nos vários níveis de gestão, quanto ao desejo do oferecimento destas práticas e terapias pelo SUS.

Quanto aos profissionais de saúde, eles têm mantido relações relativamente harmoniosas com as práticas complementares, particularmente com as de promoção da saúde, que suscitam menos disputas corporativas. Além disso, há crescente interesse dos profissionais por tais práticas e racionalidades $3,5,6,7,43,44,45$. Via de regra, nos serviços que tomam iniciativas de oferecer alguma prática complementar, ocorre colaboração dos profissionais, com uma apreciação positiva quanto à diversificação de espaços promotores que acabam sendo sempre também "terapêuticos", sob vários pontos de vista.

Um exemplo recente pode ilustrar algumas potencialidades das MAC, estudado por De Simoni 33. A oferta disseminada de grupos de lian gong (técnica com séries de exercícios físicos 
derivada da medicina tradicional chinesa) por toda a rede de Centros de Saúde de Campinas gerou entusiasmada participação de usuários do SUS, com avaliação positiva generalizada sobre sua eficácia clínica - empírica - e sobre o enriquecimento psicossocial dos participantes: a mobilização, a aceitação massiva, a melhora psicossocial e o "empoderamento" individual e microcoletivo de usuários com as mais diversas situações existenciais e problemas de saúde pôde ser observado, inclusive pelo autor destas linhas, então profissional de saúde naquele município.

Esquematizando as contribuições apresentadas das MAC à promoção da saúde, pode-se visualizá-las no mesmo quadro geral dos eixos da promoção da saúde, na Figura 2.

Assim, as práticas complementares podem ser recursos úteis na promoção da saúde indi- vidual e grupal. Sua contribuição não parece ser desprezível, ao contrário. Ela potencialmente ajuda a suprir uma falha estratégica na promoção da saúde no SUS, uma vez que a tradição dominante na ação educativa nos serviços de saúde é centrada na prevenção de doenças e controle de fatores de risco, sendo comuns o amedrontamento da população e a pouca efetividade.

Existem, é claro, dificuldades implicadas nessas contribuições, envolvendo concepções diferentes, complementares ou alternativas, no tocante aos significados e orientações para as práticas. Essas dificuldades, porém, afligem mais os profissionais de saúde, cientistas e intelectuais do que os usuários e doentes, os quais, em geral, transitam sincreticamente pelos saberes, práticas, concepções e valores das várias medicinas e técnicas sem problemas relevantes, percorrendo

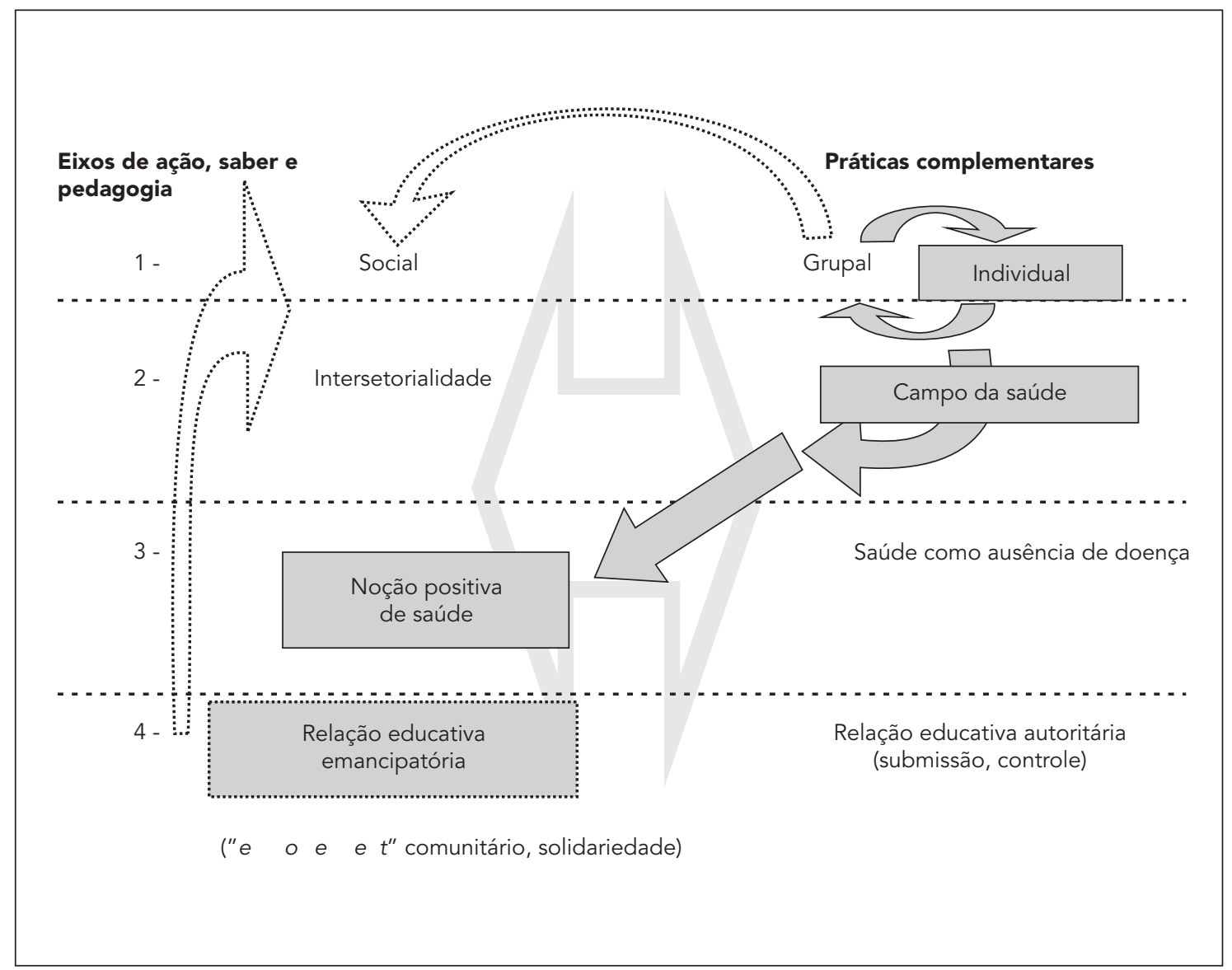


diferentes itinerários terapêuticos e, porque não dizer, promotores de saúde, quando a eles têm acesso.

No entanto, as racionalidades médicas e práticas complementares não são uma panacéia da promoção da saúde individual. Elas estão em processo de cientificização, transformando-se em procedimentos especializados mais ou menos desligados de seu contexto cultural tradicional e de suas racionalidades originais, bem como dos valores solidários e "empoderadores" caros à promoção da saúde. Juntamente com um processo de mercantilização, elas vêm sendo fragmentadas em técnicas isoladas e procedimentos no mercado alternativo/complementar e estão em transformação com a globalização. Isso remete ao último tópico.

\section{Dificuldades para legitimação das práticas complementares na promoção da saúde}

A potencialidade das práticas complementares pode ser realizada na promoção da saúde com base na suposição de que suas racionalidades, saberes e técnicas portam verdades dignas de crédito. Aqui aparece uma primeira dificuldade simultaneamente epistemológica e política. A diferenciação entre ciência e senso comum, no desenvolvimento da modernidade, induz a ignorar, desprezar e desqualificar outras verdades que não as das ciências ${ }^{10}$. Essa restrição e a subvalorização, espalhadas pelo planeta com a globalização, associam-se à supremacia científica e ao monopólio institucional da verdade adquirido pela ciência na saúde e estão ligadas a grupos sociais, corporações e relações de poder aguerridas. Isso significa uma dificuldade de maior ordem: a biociência, suas profissões e corporações correlatas (lideradas pela biomedicina) dominam a área da saúde institucional nos aspectos epistemológicos e culturais, com grande força política - que se associa, comumente, ao poderoso e vasto "complexo médico industrial". Além do mais, no seu processo de estudo e interesse pelas MAC, a biomedicina reduz algumas de suas técnicas a procedimentos e terapias isoladas, absorvendoas aos pedaços e transformando-as.

Os estudos do grupo de Luz 3,35,46 sobre as racionalidadesmédicas, as críticas deFeyerabend 47 , as crises das ciências 10,48, as crises ecológicas do mundo e muitos outros fatores parecem sustentar que esta lógica de guerra e de desqualificação pode e deve ser substituída por uma atitude mais democrática, dialogal e sincrética, no espírito da complementaridade entre distintos saberes e ações em saúde. No dizer de Santos 48, é necessá- ria uma segunda ruptura epistemológica, agora com a própria ciência, para que esta reencontre o senso comum e as outras tradições num movimento de mútuo enriquecimento.

Feyerabend 47 afirmou que as tradições diferentes da tradição teórica hegemônica nas ciências foram e continuam sendo menosprezadas por questões econômicas, militares e políticas. $\mathrm{O}$ autor defende o direito de todas poderem desenvolver-se livremente na sociedade, enquanto nelas houver interessados, inclusive com incentivo e subsídio do Estado, que não deveria ser dirigido apenas às ciências. Este autor propõe que é tempo de separar o Estado da ciência, assim como isso já ocorreu em relação à Igreja Católica no ocidente, de modo a democratizar decisões e o aprendizado de questões, inclusive na área da saúde, na qual há praticamente um monopólio de julgamento da ciência e seus especialistas sobre o que pode ou não ser considerado válido como forma de cuidado a ser oferecido às pessoas.

Outra grande dificuldade é que, no Brasil, talvez não haja atores ou instituições bem estabelecidos e vinculados a outras racionalidades médicas ou tradições de cura em número significativo e ao mesmo tempo convergentes com o ideário do SUS e da promoção da saúde, para serem, de pronto, parceiros a serem reconhecidos e valorizados como referências para práticas complementares e outras racionalidades médicas, formadores de praticantes para sua oferta no SUS.

Acrescenta-se a essa escassez, por último, o já mencionado processo de mercantilização dos saberes, técnicas e práticas complementares, que transforma este universo, sobrevaloriza certos procedimentos e técnicas heterônomas, descontextualiza e alija ou mesmo exclui outros saberes e práticas, não raro justamente os mais convergentes com os valores da promoção da saúde.

Tais dificuldades sugerem algumas diretrizes e estratégias para legitimação sócio-institucional dessas práticas, especialmente as inseridas em racionalidades médicas, na promoção da saúde no SUS. Há que diversificar o processo de validação e legitimação das práticas para além da ciência e da biomedicina: democratizar o tema e politizá-lo. A ciência pode ser um ponto de apoio para legitimação, não o único nem tampouco necessário sempre. Outros valores além dos científicos são desejáveis na promoção da saúde, bem como outros saberes de novas e antigas tradições não científicas ou ocidentais. A sociedade e os usuários podem decidir, via gestão democrática do SUS (Conselhos de Saúde), sobre a oferta e a legitimação de iniciativas de oferta das MAC aos usuários. Isso significa, em certa medida, "desepistemologizar” a discussão, ou tirá-la do marco 
positivista restrito e ingênuo em que comumente se a coloca.

Outra estratégia é fomentar ativamente, no SUS e na saúde coletiva, pesquisas, estudo, capacitação e oferta de saberes/técnicas presentes nas práticas complementares e racionalidades médicas convergentes com os valores da promoção da saúde. Isso significa garimpar os remanescentes e herdeiros destes lados promotores da saúde destas práticas, praticantes, tradições, racionalidades. Tais herdeiros e práticas (raros que possam ser e por isso mesmo) merecem preservação e fomento, pois podem contribuir na promoção da saúde no âmbito individual e grupal. A exploração dessas contribuições certamente significará, mesmo que de forma limitada, um incremento na promoção da saúde nos serviços do SUS.

\section{Resumo}

Apresentam-se contribuições das medicinas alternativas e complementares (MAC) ao campo da promoção da saúde. Após contextualização das MAC, propõe-se um esquema para visualização de desafios e tensões da promoção da saúde, organizado em quatro eixos bipolares: (1) ações voltadas para o coletivo (sociais, "empoderamento" coletivo) vs. para os indivíduos; (2) ações intersetoriais vs. setoriais; (3) concepção de saúde positiva e ampliada vs. saúde como ausência de doença; (4) pedagogia diretiva vs. dialogal. Argumentase que as contribuições das MAC à promoção da saúde são dirigidas aos indivíduos e grupos e ao pólo setorial da promoção; são centradas em concepções positivas de saúde, sobretudo as racionalidades médicas vitalistas, portadoras de práticas de fortalecimento da saúde; e com potencial pedagógico "empoderador". São apontadas a relevância dessas contribuições pouco exploradas e dificuldades e diretrizes para sua viabilização no Brasil, relacionadas às suas conformações não científicas e pouco institucionalizadas e sua progressiva mercantilização.

Terapias Complementares; Promoção da Saúde; Prática Profissional

\section{Referências}

1. Departamento de Atenção Básica, Secretaria de Atenção à Saúde, Ministério da Saúde. Política nacional de práticas integrativas e complementares no SUS (PNPIC): atitude de ampliação de acesso. Brasília: Ministério da Saúde; 2008. (Série B. Textos Básicos de Saúde).

2. National Center of Complementary and Alternative Medicine.What is complementary and alternative medicine? http://nccam.nih.gov/health/ whatiscam/\#1 (acessado em 30/Out/2008).

3. Luz MT. Medicina e racionalidades médicas: estudo comparativo da medicina ocidental contemporânea, homeopática, chinesa e ayurvédica. In: Canesqui AM, organizadora. Ciências sociais e saúde para o ensino médico. São Paulo: Editora Hucitec; 2000. p. 181-200.

4. Organización Mundial de la Salud. Estrategia de la OMS sobre medicina tradicional 2002-2005. Genebra: Organización Mundial de la Salud; 2002.

5. Barros NF. Medicina complementar: uma reflexão sobre o outro lado da prática médica. São Paulo: Annablume Editora; 2000.

6. Barros NF. Da medicina biomédica à complementar: um estudo dos modelos da prática médica [Tese de Doutorado]. Campinas: Faculdade de Ciências Médicas, Universidade Estadual de Campinas; 2002.

7. Dobson R. Half of general practices offer patients complementary medicine. BMJ 2003; 327:1250.

8. Chalhoub S, Marques VRB, Sampaio CGR. Artes e ofícios de curar no Brasil. Campinas: Editora da UNICAMP; 2003.

9. Carvalho ACD. Feiticeiros, burlões e mistificadores: criminalização e mudança das práticas populares de saúde em São Paulo de 1950 a 1980. São Paulo: Editora da Universidade Estadual Paulista; 2005. 
10. Santos BS. A crítica da razão indolente: contra o desperdício da experiência. 2a Ed. São Paulo: Cortez Editora; 2000.

11. Caprara A, Rodrigues J. A relação assimétrica médico-paciente: repensando o vínculo terapêutico. Ciênc Saúde Coletiva 2004, 9:139-46.

12. Starfield B. Is US health really the best in the world? JAMA 2000; 284:483-5.

13. Tesser CD, Luz MT. Racionalidades médicas e integralidade. Ciênc Saúde Coletiva 2008; 13:195-206.

14. Levin JS, Jonas WB, organizadores. Tratado de medicina complementar e alternativa. São Paulo: Editora Manole; 2001.

15. Astin JA. Why patients use alternative medicine: results of a national study. JAMA 1998; 279:1548-53.

16. Sharma U. Complementary medicine today: practitioners and patients. New York: Tavistock; 1992.

17. Fulder S. The handbook of alternative \& complementary medicine. London: Vermilion; 1996.

18. Ernst E, organizador. Medicina complementar: uma avaliação objetiva. São Paulo: Editora Manole; 2001.

19. Andrade JT. Medicinas alternativas e complementares: experiência, corporeidade e transformação. Salvador: Editora da Universidade Federal da Bahia; 2006.

20. Tesser CD, Barros NF. Medicalização social e medicina alternativa e complementar: pluralização terapêutica do Sistema Único de Saúde. Rev Saúde Pública 2008; 42:914-20.

21. Buss PM. Promoção da saúde e qualidade de vida. Ciênc Saúde Coletiva 2000; 5:163-77.

22. Buss PM. Uma introdução ao conceito de promoção da saúde. In: Czeresnia D, Freitas CM, organizadores. Promoção da saúde: conceitos, reflexões, tendências. Rio de Janeiro: Editora Fiocruz; 2003. p. 15-38.

23. Carvalho SR. Saúde coletiva e promoção da saúde: sujeito e mudança. São Paulo: Editora Hucitec; 2005.

24. Sícoli JL, Nascimento PR. Promoção de saúde: concepções, princípios e operacionalizações. Interface Comun Saúde Educ 2003; 7:101-22.

25. Lefevre F, Lefreve AMC. Promoção de saúde: a negação da negação. Rio de Janeiro: Vieira \& Lent Casa Editorial; 2004.

26. Czeresnia D. The concept of health and the difference between prevention and promotion. Cad Saúde Pública 1999; 15:701-9.

27. Ministério da Saúde. Anexo 1. Política nacional de promoção da saúde. http://portal.saude.gov.br/ portal/arquivos/pdf/portaria687_2006_anexo1. pdf (acessado em 13/Ago/2007).

28. Castiel LD, Diaz CAD. A saúde persecutória: os limites da responsabilidade. Rio de Janeiro: Editora Fiocruz; 2007.

29. Sutherland RW, Fulton MJ. Health promotion. In: Sutherland RW, Fulton MJ, editors. Health care in Canada. Ottawa: Canadian Public Health Association; 1992. p. 161-81.

30. Campos RO. A promoção da saúde e a clínica: o dilema "promocionista". In: Castro A, Malo M, organizadores. SUS: ressignificando a promoção da saúde. São Paulo: Editora Hucitec; 2006. p. 462-741.
31. Czeresnia D. O conceito de saúde e a diferença entre prevenção e promoção. In: Czeresnia D, Freitas CM, organizadores. Promoção da saúde: conceitos, reflexões, tendências. Rio de Janeiro: Editora Fiocruz; 2003. p. 39-53.

32. Carvalho SR. Os múltiplos sentidos da categoria "empowerment" no projeto de Promoção à Saúde. Cad Saúde Pública 2004; 20:1088-95.

33. De Simoni CL. Ginástica terapêutica chinesa Lian Gong: estudo de caso da inserção no SUS [Dissertação de Mestrado]. Salvador: Instituto de Saúde Coletiva, Universidade Federal da Bahia; 2005.

34. Freire Jr. MB. Conhece-te a ti mesmo: uma proposta de educação popular para a saúde. Saúde Debate 1993; 41:4-8.

35. Luz MT. Racionalidades médicas e terapêuticas alternativas. Rio de Janeiro: Instituto de Medicina Social, Universidade do Estado do Rio de Janeiro; 1996. (Série Estudos em Saúde Coletiva, 62).

36. Tesser CD. Epistemologia contemporânea e saúde: a luta pela verdade e as práticas terapêuticas [Tese de Doutorado]. Campinas: Faculdade de Ciências Médicas, Universidade Estadual de Campinas; 2004.

37. Jianping H. Metodologia da medicina tradicional chinesa. São Paulo: Editora Roca; 2001.

38. Jullien F. Um sábio não tem idéia. São Paulo: Editora Martins Fontes; 2000.

39. Jullien F. Fundar a moral: diálogo de Mêncio com um filósofo das Luzes. São Paulo: Discurso Editorial; 2001.

40. Goleman D. A mente meditativa: as diferentes experiências meditativas no oriente e no ocidente. $5^{\mathrm{a}}$ Ed. São Paulo: Editora Ática; 1997.

41. Kaiguo C, Shunchao Z. La puerta del dragón: relato de la iniciación de un maestro taoísta contemporáneo. Madrid: Editorial EDAF; 1998.

42. Maheshvarananda D. Após o capitalismo: a visão de Prout para um novo mundo. Belo Horizonte: Proutista Universal; 2004.

43. Vasconcelos EM. A espiritualidade no cuidado e na educação em saúde. In: Vasconcelos EM, organizador. A espiritualidade no trabalho em saúde. São Paulo: Editora Hucitec; 2006. p. 13-160.

44. Salles SAC. Homeopatia, universidade e SUS: resistências e aproximações. São Paulo: Editora Hucitec; 2008.

45. Davis-Floyd R, St. John G. Del médico al sanador. Buenos Aires: Creavida; 2004

46. Luz MT. Cultura contemporânea e medicinas alternativas: novos paradigmas em saúde no fim do século XX. Physis (Rio J.) 2005; 15 Suppl:145-76.

47. Feyerabend P. Adeus à razão. Lisboa: Edições 70; 1991.

48. Santos BS. Introdução a uma ciência pós-moderna. Rio de Janeiro: Editora Campus; 1982.

Recebido em 04/Nov/2008

Versão final reapresentada em 13/Fev/2009

Aprovado em 13/Abr/2009 